\title{
CONSTRUÇÃO DE SENTIDO NAS NARRATIVAS DE DOENTES CRÔNICOS
}

José Roque Junges ${ }^{1}$, Tatiane Bagatini $2^{*}$

Trabalho realizado na Universidade do Vale do Rio dos Sinos - UNISINOS, São Leopoldo, RS

*Correspondência:

Rua Santo Antônio, 1166 1404

Centro - São Leopoldo - RS

CEP: 93010-280

tbagatini@yahoo.com.br

\begin{abstract}
RESUMO
OBJetivo. Entender o modo como os doentes crônicos ressignificam a vida por meio de suas práticas discursivas.

Métodos. Foram selecionadas seis entrevistas de um total de 17 realizadas com doentes crônicos de um hospital público da região metropolitana de Porto Alegre. As entrevistas gravadas e transcritas produziram narrativas sobre a situação existencial ante à doença, as perspectivas de futuro, a compreensão do diagnóstico e da terapêutica e o papel dos profissionais na ressignificação. As falas foram divididas em repertórios linguísticos sobre o diagnóstico e sobre a terapêutica.

Resultados. Nos primeiros, as narrativas de sentido estão construídas ao redor da causa da doença de fundo genético (destino) ou devido ao estilo de vida (culpa). Nos repertórios sobre a terapêutica as narrativas de reconfiguração da identidade pessoal (self) dependem da autonomia ou da heteronomia diante da palavra do médico como mediador de salvação, da percepção do corpo como fator de relação, da representação social do medicamento e da situação emocional.

Conclusão. A autosatisfação depende de encontrar o fio para costurar os elementos da existência a partir de um novo molde de sentido possibilitando uma nova identidade. O profissional precisa estar atento às narrativas de reconstrução da identidade para que os meios terapêuticos produzam o efeito esperado e o enfermo se sinta sujeito do processo, assumindo com autonomia as mudanças necessárias em sua vida.
\end{abstract}

Unitermos: Doença crônica. Diagnóstico. Terapêutica. Narrativas pessoais. Individualidade.

\section{INTRODUÇÃO}

O uso de tecnologias nas práticas de saúde do Sistema Único de Saúde (SUS) permite democratizar o acesso a tratamentos de alta complexidade. A introdução de aparelhos e medicamentos de última geração trouxe grandes benefícios, possibilitando diagnósticos mais precisos e terapias mais específicas. Esta sofisticação tecnológica pode trazer um efeito colateral, nem sempre percebido pelos profissionais, de uma redução da terapêutica a processos técnicos. A crença na onipotência da técnica pode fazer esquecer a importância da qualidade da relação entre o profissional e o usuário.

Ciente deste fato, o Ministério da Saúde (MS) lançou o Programa Humaniza SUS no sentido de criar a Política Nacional de Humanização (PNH). Essa preocupação responde ao princípio da integralidade, uma das bases conceituais do SUS. O nível de acolhimento e de vínculo são indicadores fundamentais da construção de integralidade na saúde. Trata-se de dimensões da prática que vão além do uso de tecnologias porque atingem a subjetividade do usuário e do próprio trabalhador. A intenção do MS é construir e pactuar uma política que assuma a humanização como eixo das práticas de atenção e gestão do SUS ${ }^{1}$.
Numa situação de doença crônica, a reação do sujeito ante ao seu quadro torna-se essencial para a consecução da integralidade no tratamento. A reação significa a construção de um sentido para a nova situação existencial no âmbito da linguagem, a construção de uma nova subjetividade por meio das práticas discursivas entre os profissionais e os usuários durante o tratamento. Os profissionais ocupam um lugar importante nestas práticas, escutando a narrativa dos doentes e fornecendo informações sobre a sua situação.

A Política Nacional de Humanização pretende resgatar o valor da linguagem na relação profissional-usuário, inserindo o uso das tecnologias nos contextos das práticas discursivas, ajudando os usuários na construção de sentido de sua nova situação subjetiva.

\section{MÉtodos}

A pesquisa O Ambiente Sociocultural no Processo de Ressignificação da Vida frente à Doença e o Papel dos Profissionais, executada por pesquisadores do programa de pósgraduação em Saúde Coletiva da UNISINOS objetivou entender o modo como doentes crônicos reagem em sua subjetividade

1. Doutor em Ética Teológica, pós-doutor em Bioética e professor e pesquisador do programa de pós-graduação em Saúde Coletiva na Universidade do Vale do Rio dos Sinos - UNISINOS, São Leopoldo, RS

2. Especialista em Psicologia Social e Institucional pela Universidade Federal do Rio Grande do Sul - UFRGS e Psicóloga da Prefeitura Municipal de São Leopoldo, São Leopoldo, RS 
diante da enfermidade. A pesquisa é qualitativa, utiliza para a coleta de dados a entrevista semiestruturada e como abordagem investigativa a análise do discurso. Na entrevista foram explorados os temas: a) situação existencial atual como enfermo; b) como vê e compreende o diagnóstico da sua doença; c) como vê e assume a terapêutica; d) quais as perspectivas de futuro ante à doença; e) como vê a atuação dos profissionais em relação à situação de enfermidade.

A amostra foi composta de adultos entre 25 a 65 anos com diagnóstico de doença crônica internados num hospital público da região metropolitana de Porto Alegre. Para análise foram selecionadas seis entrevistas de um universo de 17 pela riqueza e detalhamento das narrativas. As pacientes entrevistadas eram mulheres. Seus nomes foram substituídos por nomes de flores: Adélia, Camélia, Hortência, Margarida, Rosa e Violeta. A pesquisa foi aprovada pelo Comitê de Ética da UNISINOS com a Resolução no. 053/2004.

As narrativas foram interpretadas na perspectiva da análise do discurso proposta por Bakthin², que tem como ponto de partida a linguagem em uso ou o papel da linguagem na interação social e como base a compreensão da linguagem como matriz de construção de sentido. O foco são as práticas discursivas, ou seja, as maneiras como as pessoas produzem sentidos por meio da interação social da linguagem. Isso significa uma superação da visão representacionista do mundo na linguagem e a assunção de uma concepção construcionista da realidade por meio dos sentidos construídos e expressos na interação linguística.

Essa metodologia é adequada ao foco da pesquisa porque tenta ver como as práticas discursivas dos enfermos constroem um sentido para a doença ou como na interação da linguagem a pessoa vai construindo os sentidos que moldam a trama da sua vida. A análise do discurso trabalha com repertórios linguísticos nas unidades básicas de comunicação, que são os enunciados. 0 enunciado, como unidade básica de comunicação, compreende da pergunta até a finalização da resposta. Para compreender o sentido é necessário ter os elos da cadeia de comunicação presentes na interanimação dialógica².

O enunciado tem como características: a) fronteiras: demarcadas pela mudança do sujeito da fala que finaliza a reação de resposta, definindo os limites do enunciado; b) endereçamento: direciona a resposta ou reação ao enunciado que o precedeu, expressando a dialogicidade da linguagem; c) gêneros de fala: paradigmas relativamente estáveis de fala que formam o substrato compartilhado que possibilita a comunicação em determinados ambientes. A prática discursiva é um encadeamento de endereçamentos, uma interanimação dialógica; a linguagem é sempre endereçada, não existindo monólogo. A sala de aula, a consulta médica, a situação de um funeral instauram diferentes gêneros de fala².

Essas características apontam para a dinâmica da prática discursiva, que põem em movimento conteúdos presentes nos repertórios linguísticos - as palavras, os conceitos, as metáforas, as frases enucleadas num enunciado. Assim, as práticas discursivas possibilitam a construção de sentidos, a interação dialógica e a tomada de posicionamento.

O sentido é uma construção interativa do sujeito para compreender e lidar com situações e fenômenos de seu cotidiano. Acontece sempre numa interação dialógica com outros: entorno social e destinatários dessa construção. No processo discursivo há construção de subjetividade, pois ao tentar lidar com o seu cotidiano conferindo-Ihe sentido, acontece uma tomada de posição enquanto sujeito. Assim, ele ressignifica a vida na prática discursiva apropriando-se interativamente dela como sujeito $3,4,5,6,7$.

As narrativas, por terem sido produzidas no contexto hospitalar, se aproximam do gênero textual da entrevista clínica, embora não aconteça nenhuma intervenção direta de médico, mas apenas a rememoração do itinerário clínico e o contexto existencial no qual ele aconteceu. 0 estilo é narrativo e a sequência é dialógica por tratar-se de uma entrevista semiestruturada com o enfermo.

Seguindo Spink ${ }^{5}$ et al. ${ }^{8}$, as falas transcritas foram organizadas em mapas de associação de ideias. Tendo presente o gênero de fala, o primeiro mapa recolheu relatos sobre a doença (diagnóstico), dividido em duas colunas: falas sobre por que está doente; como surgiu a doença. O outro mapa apresenta discursos sobre o tratamento (terapêutica), subdividido em quatro colunas: falas sobre as práticas clínicas dos médicos; prescrições de dieta e exercícios; uso de terapias alternativas; contexto emocional do tratamento.

A leitura repetida destes mapas com seus repertórios lingüísticos e enunciados possibilitou desenhar árvores de associação para, a partir daí, chegar às práticas discursivas de produção de sentido. Alguns destes repertórios com suas práticas discursivas de construção de sentido chamaram atenção pela íntima relação com a construção de sentido para a doença crônica. A separação das falas em mapas que discorrem sobre a doença e sobre o tratamento sinaliza diferenças significativas para a construção de sentido.

\section{Resultados e discussão}

\section{Diagnóstico da doença}

Sobre o diagnóstico, algumas pessoas assimilaram noções atuais da etiologia das doenças no seu discurso significante: estilo de vida e genética familiar como causas. Mas, a percepção destas realidades acontece a partir dos esquemas tradicionais: doença como culpa e doença como destino.

Rosa, uma paciente com insuficência renal, culpabiliza-se dizendo: "Ah, eu fico às vezes bem triste porque eu penso que fui comer essas coisas que não podia. Agora já é tarde. Agora tem que levar a vida".

Violeta, paciente com diabetes, diante da pergunta "Como é que a senhora está vendo a sua doença?" afirma: "Eu acho que foi culpa minha porque o meu marido me dizia para não comer coisa doce, não tomar isso e aquilo. Eu sou teimosa e estou aqui agora".

Camélia, paciente com diabetes e hipertensão, responde ao endereçamento da entrevistadora " $A$ senhora chega a ter alguma culpa por estar assim ou não?", retrucando que "Não, se eu procurei, é porque eu quis. Não me sinto culpada". Pela negativa, esta assume a responsabilidade pelo estilo de vida sem culpabilizar-se.

Adélia também com diabetes e hipertensão diante da pergunta: "A senhora sente talvez alguma culpa por ter diabetes?", retruca: "Não, porque isso é uma coisa que vem de família, porque os velhos tinham, minha mãe, meu pai e 
todos os irmãos. Alguns já morreram". Com a pergunta: "Como é que a senhora vê a doença?", Adélia relaciona sua situação com o destino: "A doença eu vejo como uma coisa que tem que acontecer, é o destino. Existe a saúde e a doença; se existe saúde tem que existir a doença também". Na palavra de Adélia aparece claramente a compreensão da doença familiar como destino. A inevitabilidade da doença familiar, apresentada pela ciência como algo genético, é representada pela cultura popular como destino.

Os hipertensos afirmam com mais ênfase a etiologia familiar. Margarida ante ao endereçamento da pergunta: "Como é que sentiu quando teve que parar de trabalhar?" ela explica que foi difícil porque teve que deixar o emprego e porque trabalhou direto sem férias, mas logo envereda pela explicação familiar: "Quanto ao problema do coração, eu tenho uma família cardíaca. Meu pai teve infarto, minha mãe tem três pontes de safena, a família do meu pai também tem". Volta a falar que sempre trabalhou muito e corta novamente, fazendo um discurso sobre a família: "A minha família tem muito problema de pressão, tanto a do pai quanto a da mãe, tenho tios que morreram de infarto, novos. Eu sou uma candidata a isso". Em outras palavras, ela está dizendo que a causa não é um estilo de vida, o muito trabalho, mas a doença genética da família.

Hortência, paciente hipertensa, ante ao endereçamento da entrevistadora: "Foi só agora que a senhora descobriu que tem problema no coração ou faz tempo?", ela refere: "Faz tempo, porque nós somos de família cardíaca". Diante de outra pergunta: "A senhora sempre teve que se cuidar do coração ou só agora? ela retruca: "Não, a nossa família é assim, eu tenho bronquite também". E diante da questão: "Como é que a senhora está vendo a doença?", ela interpreta: "Eu acho que quando a gente veio para cá a gente já veio com aquele destino pronto". O enunciado manifesta claramente o esquema do destino numa enfermidade de base familiar.

Aparecem dois tipos de construção de sentido em relação à causa da enfermidade: a responsabilidade pessoal pelo estilo de vida que provocou a doença com sensação frequente de culpa e a inserção numa linhagem genético-familiar de doença geralmente ligada ao destino. Estas etiologias reeditam causas típicas do imaginário religioso tradicional: doença como causa do pecado pessoal ou doença como algo mandado por Deus ou por alguma entidade espiritual. Hoje se difunde também dois tipos de etiologias, mas a partir de outro imaginário criado pela mentalidade científica médica: o estilo de vida que responsabiliza o enfermo e a herança genética que, ao contrário, desresponsabiliza.

Essas etiologias de cunho científico são interpretadas, muitas vezes, a partir do imaginário tradicional da culpa e do destino. Por isso, na construção de sentido, a herança genética tem um trânsito mais fácil, pois insere a doença numa linhagem familiar que ajuda a ressignificar. A herança genética é interpretada no modelo da herança familiar, o que aparece nos enunciados pelas reiteradas afirmações de que pai, mãe e tios já tiveram essa doença. A inserção da enfermidade pessoal numa linhagem familiar da doença ajuda a integrá-la e a encontrar um sentido para ela. A enfermidade torna-se um quase comprovante do pertencimento àquela família. A construção de sentido acontece por esse pertencimento sinalizado pela própria doença.

\section{Tratamento terapêutico}

Quanto à terapêutica aparece a diferença entre a heteronomia da obediência ao médico e a autonomia do enfermo na busca de soluções complementares. Praticamente todas as entrevistadas afirmam que o tratamento e a cura dependem do seguimento das determinações do médico.

Margarida, uma paciente com hipertensão e lupus erimatoso, diante da pergunta: "É uma doença que é preciso controlar, que não tem cura. E o que tu fazes para melhorar?", constrói o enunciado sobre a necessidade de controlar o lupus para não se alastrar, recorrendo à autoridade do médico: "Uma coisa que o médico sempre disse para mim que eu tenho que cuidar da depressão, porque é uma das coisas que mais derruba e o organismo não reage". "O médico disse que um pouco foi do trabalho direto sem férias".

Depois de falar do que causa a doença, segundo o médico, Margarida discorre sobre como lidar com os sintomas, contando que tem dias que não tem vontade de sair, fecha a porta, mas sempre chega alguém para levá-la para passear na rua. Introduz novamente a autoridade do médico para confirmar: "O médico sempre diz que não pode deixar isso acontecer porque isso que é o pior da doença".

O discurso de Margarida está construído, por um lado, em torno da palavra imperativa do médico e, por outro, da compra e eficácia dos remédios. O estado psicológico de depressão pode explicar essa dupla dependência como fatores de apoio emocional numa situação de insegurança de abandono. A palavra de comando do médico serve de fio para costurar o discurso que tece a construção de sentido para Margarida. Ela não tem condições de buscar por si a solução, preferindo entregar-se ao que é mandado pelo médico.

Violeta, diante do endereçamento da entrevistadora: "O que a senhora acha que vai acontecer agora que descobriu que tem diabetes? Como é que a senhora vê a doença?" ela enuncia: "Ah, eu acho que se eu fizer o meu tratamento certinho, comer o que o doutor disser, daí vai ter salvação. Se eu fizer tudo errado, eu não vou me recuperar nunca". Para Violeta, o médico é mediador de salvação ou perdição. Ela também se encontra numa situação de depressão, que a faz submeter-se àquele que pode the oferecer a salvação e se não seguir as recomendações não terá salvação. Não acontece a apropriação pessoal da sua doença e uma decisão sobre como agir porque a saúde é esperada de um mediador externo.

Nos casos de Margarida e Violeta, não existe autonomia em relação à condução da sua doença e na busca de uma via saudável para conviver com a doença crônica. Seguindo Illich ${ }^{9}$ pode-se afirmar que saúde identifica-se com autonomia porque significa capacidade de reagir diante de uma situação tendente a desequilibrar a vida. Sem relativa autonomia torna-se difícil a construção de sentido numa situação de doença crônica. Essa autonomia depende em última análise da configuração da identidade pessoal.

Para entender esse fenômeno pode-se introduzir a noção de identidade do eu (self), desenvolvido no campo das Ciências Sociais por Giddens ${ }^{10}$. Ele parte da premissa de que ser pessoa significa praticamente a capacidade de descrever o que se faz e por que se faz. A consciência reflexa é base de qualquer ação humana e cria a confiança básica de poder levar adiante a sua 
doença crônica particular. A identidade de uma pessoa não é construída pelo comportamento nem mesmo pelas relações, mas na capacidade de manter uma narrativa da vida, pois, por meio dela se constrói o sentido dos acontecimentos e se adquire autonomia.

Ricoeur ${ }^{11}$ foi o autor que mais trabalhou essa relação entre identidade e narrativa, pois, na narrativa, o indivíduo tem uma compreensão de si próprio porque consegue reunir numa síntese existencial os fragmentos da vida. Por isso, é na narrativa que consegue costurar uma unidade existencial que permite ver continuidade e identidade nos acontecimentos e acidentes que compõem a trajetória da vida e manifestar autonomia.

Margarida e Violeta manifestam quadros depressivos que as fragilizam, tornando-as dependentes, para costurar as adversidades na trama biográfica da vida com um fio de sentido. Por isso, têm dificuldade de integrar a doença na identidade do eu. Isso aparece na narrativa de Margarida, pois ela é construída com elementos externos à vida: o médico e os remédios. Violeta, apesar do quadro depressivo e da dependência, consegue lidar melhor com a situação emocional, pois as referências da sua narrativa biográfica são os filhos.

Hortência, com Acidente Vascular Cerebral (AVC) agudo, manifesta maior autonomia, pois relativiza o médico, confiando também em outras ajudas. Diante da pergunta: "Quem mais ajuda a senhora no hospital?", responde: "Olha, eu acho que é a psicóloga. A gente pode desabafar, falar bastante, eu choro, eu falo. Não é só fazer uma injeção ou dar um remédio para dormir. Eu acho assim que é melhor sentar e conversar do que dar um remédio". Esta independência ante à intervenção do médico vem da existência de outros fatores de apoio e proteção como família, amizade e religião que são a base da autoconfiança para construir a trama biográfica. Isso aparece na sua narrativa quando diz que é melhor conversar do que tomar remédio. Ela constrói sua narrativa com elementos que fazem parte do seu cotidiano.

Diante do endereçamento: "O que faz a senhora ser tão animada, tão pra cima?" Hortência responde: "Eu acho assim que Deus me deu as três coisas que eu mais amo no mundo que são meus filhos. Tudo vale a pena por um filho". Aqui está a causa para ir à luta e não desanimar ante à doença. Quanto à amizade, enuncia: "Eu sou uma pessoa que faz muita amizade, eu tenho uma cara desse tamanho. Eu gosto, assim de ter amizade, eu gosto de conversar com as pessoas, é tão bom porque a vida já é tão dura e a gente só vai pensar coisa triste é pior!". Esta é a causa para não se queixar. Quanto à religião, afirma: "Eu rezo de noite agradeço a Deus. Eu converso muito com Deus de noite. Eu digo assim: eu não vou Ihe pedir mais nada, eu só quero agradecer pelos meus filhos". Estas constantes levam Hortência a ir à luta ("cada dia a gente luta"), não se queixar ("não adianta a gente se queixar porque quanto mais se queixa, sabe aquela coisa negativa, aquilo vai puxando"), buscando ajuda psicológica para construir a trama biográfica como complemento da terapia clínica, demonstrando autonomia e autoconfiança na busca de ajuda para além do médico.

Nos repertórios de falas sobre o tratamento três elementos incidem nas narrativas que relatam a desestruturação da doença; três realidades com significados simbólicos para o discurso de construção de sentido: corpo, medicamento e situação emocional.

\section{Corpo}

Rosa, paciente com insuficiência renal crônica, necessitando de um transplante de rim, ao falar como surgiu a doença, constrói a seguinte árvore de associação relativa ao seu corpo pessoal, diante do endereçamento da pergunta: "E quando tu descobriste que precisava fazer hemodiálise?":

(1) Descobri por causa da pressão alta

(a) quando estava grávida

- baixei hospital

- corpo muito pesado, caminhava com aquele peso

- barriga sempre pesada, sempre estufada

(b) fui ganhar na maternidade

- estava com pés inchados e cento e poucos quilos, era tudo líquido no corpo.

(2) "Fui fazer exame, uma ecografia, tive que fazer hemodiálise"

- "estava toda inchada, era tudo líquido"

- "eu me sentia cansada, pesada"

(c) "Quando fui ganhar a criança parecia que ia ganhar mais de um nenê".

A sensação do corpo com insuficiência renal é descrita por Rosa como algo pesado, estufado, inchado, associado à experiência da própria gravidez, cujo contexto foi descoberta a anomalia no rim. O corpo é sentido como contendo algo que está a mais, que precisa ser retirado. Rosa associa a doença e a gravidez com sua sensação corporal de peso. 0 modo de discursar mostra um sentimento negativo em relação a seu corpo devido ao estereótipo cultural de um corpo enxuto, leve e magro. As metáforas pesado, estufado, inchado usadas por ela ajudam a expressar o mal estar da sua experiência da doença. As metáforas constituem uma estratégia discursiva para os casos de experiência de aflição ${ }^{12}$.

Esta mesma paciente ao falar das intervenções clínicas do tratamento cometeu uma implicatura conversacional porque a entrevistadora mudou o endereçamento da conversa que discorria sobre a necessidade de um transplante, perguntando "E tu tens bastantes amigos?". Ela respondeu: "Tenho, mas tem que ser irmão para dar certo mesmo", iniciando uma longa conversa sobre a negativa dos irmãos em fazer exames para comprovar a compatibilidade para doação de rim que pode ser esquematizada na seguinte árvore de ideias construída ao redor da experiência do corpo social familiar:

(1)"O corpo da gente é difícil de aceitar dos outros";

(a)"Doutora mandou até vir os irmãos para conversar, para explicar que isso não é doença"; "Eles nunca me dão o rim nunca me ajudam";

(b)"Eu larguei de mão e nem vou mais na casa deles, é que meu marido fica me enchendo o saco";

(c)"A doutora já mandou um papel pra eles irem lá conversar - Mas eles não querem ir";

(2)"Se é para dar com medo então é melhor deixar assim... chega lá na hora e dá zebra".

Além da sensação negativa de peso corporal, aparece o desenraizamento familiar, fundado no corpo comum, devido a negativa dos irmãos em conversar com a doutora para ver a possibilidade de doação de rim. O corpo não é puro fenômeno biológico, mas muito mais sociocultural e, por outro lado, o 
próprio ambiente social é configurado pela construção cultural dos corpos que nele vivem ${ }^{13,14}$. Assim, a rejeição dos irmãos corrobora a sensação corporal negativa de Rosa e instaura a divisão no corpo social da família, expressado na motivação da negação de ir falar com a doutora que, aqui exprime o contrário da esperada solidariedade familiar. Para Rosa, a motivação para a doação é uma condição para o êxito do transplante. A negativa dos irmãos significa o corte e o desenraizamento enquanto elo do corpo social familiar dificultando a construção da sua identidade corporal nesta nova situação existencial, sendo a base psicológica para uma boa terapêutica neste caso.

$\mathrm{O}$ aparecimento de uma doença pode ser um fator de enraizamento num corpo social familiar porque se tem uma anomalia já presente nos pais ou avós. Nesse caso, a consanguinidade na doença expressa as relações de parentesco e ajuda a integrar a anomalia na identidade pessoal. Ao contrário, a negação dos irmãos de Rosa em submeter-se ao teste da compatibilidade provoca uma ruptura na consanguinidade de parentesco, pois a identidade social da família, estruturada a partir das relações entre afins e consanguíneos, se fragmenta. A negação da doação no caso de Rosa provoca a ruptura no corpo social familiar expressando-se na experiência pessoal do corpo que é base da consanguinidade ${ }^{15}$.

\section{Medicamento}

Margarida, com hipertensão e lupus erimatoso, ao falar do tratamento, diante da pergunta: "E fora os médicos, quem mais te ajuda?", inicia um longo discurso sobre a ajuda dos familiares na compra de remédios. Aparece a seguinte árvore de ideias:

(a) "eu tenho dívida na farmácia".

(b) "fiz 21 dias de antibióticos. Gastei 300 reais".

(c) "Eu tenho que tomar aquela medicação, então eu compro fiado na farmácia".

(d) "...Porque pelo SUS não se consegue nada de medicação".

(e) “Aí tenho medicação do coração e da pressão que tenho que tomar direto. Tomo sempre Monocordil, um dilatador de artérias".

(f) "Quando saí do trabalho, eu gastei todo o meu dinheiro".

0 medicamento aparece como mercadoria, ligado à preocupação de Margarida com a falta de dinheiro e a necessidade da compra do remédio, apontando para a reificação da saúde como algo que se pode consumir, adaptando a saúde á lógica do mercado. 0 medicamento é o ícone da resolução tecnológica da saúde oferecida pelo mercado que substitui a solução natural. Por isso, sabe o nome do remédio (Monocordil). A saúde quimificada em mercadoria a ser comprada e tomada ${ }^{16}$.

No mercado, tudo tem um valor de troca e um valor de uso. $\mathrm{Na}$ mercadoria medicamento, o valor de uso fica na dependência do médico que controla o uso eficaz do remédio. No consumo de medicamentos o consumidor não se torna independente, mas, ao contrário, dependente daquele que o prescreve. Essa característica pode ser notada na paciente Margarida que é muito preocupada com o uso de medicamentos e manifesta uma grande dependência do médico. O valor de uso do medicamento abre para a sua dimensão simbólica ligada a figura do médico uma mediação necessária na sua aquisição para que aconteça a eficácia simbólica do remédio ${ }^{17}$.
Diante da pergunta: "Como é que tu vês a tua doença? Como ela aparece para ti?", envereda por um discurso sobre a eficácia do medicamento:

(a) "parece que não funciona a medicação"

(b) "Tem semanas que dá vontade tomar tudo de uma vez para ver se melhora logo"..."ou parar de tomar o remédio ou tomar tudo de uma vez para ver o que dá"

(c) "Geralmente tomo sete comprimidos por dia, já cheguei a tomar 12 por dia"

(d) "Já estou tomando medicamento para o estômago, engordei um monte. Como vou fazer dieta e ficar de estômago vazio se eu tenho que estar sempre tomando remédio".

Aqui aparece o medicamento como símbolo, pois detém um significado que produz o que representa, a saúde. Nesse sentido, o simbólico determina a eficácia do remédio. A sensação expressa por Margarida é que a medicação não funciona, pois não produz a eficácia esperada. Por isso, ela tem vontade de largar os remédios devido a ineficácia do agente químico ou, o contrário, tomá-los todos de uma vez, confiando na eficácia milagrosa e inesperada do simbólico ${ }^{16}$, isto é, "para melhorar logo" ou "para ver o que dá".

\section{Situação emocional}

Violeta, com diabete e hipertensão, diante da pergunta: "Como é que a senhora está vendo a sua doença?" culpabiliza-se pela sua situação: "Eu acho que foi culpa minha de eu estar assim porque meu marido me dizia para não comer coisa doce, não tomar isso e aquilo. Eu sou teimosa e estou aqui agora". Ao falar do tratamento, ela relata a verdadeira causa ligada à sua situação emocional. Ante ao relato de que estava desleixada consigo, a pergunta: "A senhora está se gostando mais agora?", iniciando um discurso longo sobre a situação emocional provocada pela perda do filho, esquematizada na árvore de ideias:

(a) " não gostava de mim...vontade de me matar

- eu perdi meu filho, mataram um filho meu... está doendo tanto".

(b) "Todos os dias penso nele

- mataram ele. Eu perdi dois filhos, um de 16 e esse de 20".

(c) "fiquei doente, deprimida, angustiosa, um aperto, só pensando nele".

(d) "dá saudade dele, eu me arrumo,.. compro uma flor, rezo para ele e fico lá (no cemitério) com ele..daí passa aquela angústia".

Diante da pergunta: "A senhora acha que ficou doente por causa disso?, ela afirma: "É, eu acho que é por causa disso porque eu não tinha pressão alta, problema do coração e depois que ele morreu eu fiquei assim doente, deprimida, angustiada". Para ela, essa é a verdadeira causa da enfermidade e se a perda emocional não for trabalhada, os agentes químicos terão pouca eficácia. A terapêutica teria que incluir ajuda psicológica. A própria culpabilização da diabetes pelo estilo de vida explica-se pela situação de depressão advinda da perda emocional do filho.

Hortência, ao contrário, mantém boa situação emocional, pois reage mudando o molde expresso em duas atitudes: "não se queixar" e "lutar". "Não adianta se queixar porque quanto mais a agente se queixa, sabe aquela coisa negativa, aquilo vai puxando". Para uma vizinha de cama que se queixava, 
Hortência aconselhou: "Eu disse para ela, quanto mais tu te queixas é pior, não adianta a gente tem que falar em coisa boa. Eu disse assim: abre a janela, olha lá fora que coisa mais linda que tá o céu. Tem que ver ao redor e não só ficar vendo a doença". Não se queixar significa para Hortência desviar a atenção da dor e da doença, sair de si e tentar olhar ao redor, fixando o olhar na flor ou no céu.

Essa reação é possível porque ela tem apoio afetivo na família, na amizade e na religião, o que ajuda na construção de sentido. Não se queixar significa para Hortência ir à luta: "Lutar e se ajudar cada dia, um pouquinho cada dia". Ela acrescenta que valeu a pena pelos filhos: "Eu não vou Ihe pedir mais nada, eu só quero agradecer pelos meus filhos". A força para lutar vem da ligação afetiva com os filhos que serve de molde para encontrar sentido na adversidade, ressignificado a vida ante à doença crônica.

Rabelo et al. ${ }^{18}$ enfatizam que a situação emocional depende de como é constituído o self da pessoa. Ele não é um atributo fixo e permanente da pessoa, mas algo que vai sendo forjado na interação social. Trata-se de um fenômeno fluido com alta plasticidade dependente das relações. Mead ${ }^{19}$ concebe o self como a capacidade do indivíduo tornar-se objeto para si mesmo, mas isso é possível pela interação. $\mathrm{O}$ indivíduo torna-se objeto para si mesmo à medida que interioriza a perspectiva do outro.

Isso aparece nos relatos de Violeta e Hortência, pois conseguem reconstruir o self na perspectiva dos filhos. Violeta teceu o seu self no cultivo da memória do filho assassinado, cuja falta e dor provocou a doença, enquanto Hortência o reconfigurou no agradecimento a Deus pelos filhos que tem e pelos quais tudo vale a pena.

A construção de sentido depende dessa tessitura do self por meio dos fios das emoções provocadas pelas dinâmicas relacionais presentes na situação. Quanto mais ricas forem essas dinâmicas, como aparece claramente no caso de Hortência, mais chances de reconfiguração do self, encontrando um significado para as vivências, embora sofridas e traumáticas. Violeta, ao contrário, tem a tendência de isolar-se, concentrando a dinâmica emocional na memória da perda do filho. O self é tecido na lembrança emocional do filho ao levar uma flor ao túmulo. Assim, a situação emocional é base da ressignificação ante à doença porque fornece os fios relacionais para tecer a reconstituição do self ${ }^{18}$.

Essa reflexão aponta para a necessidade de superar a abordagem de saúde e doença na perspectiva do indivíduo biológico como pura repetição de uma universalidade fisiológica e pensála como experiência original de um ser singular na perspectiva relacional da pessoa gerada na interação social da linguagem ${ }^{20}$.

\section{Conclusão}

Hoje, há maior consciência das inevitáveis interferências da subjetividade na terapêutica da doença crônica, pois a autosatisfação pessoal é a base para ter qualidade de vida nesta situação, assumindo um estilo adequado ao desequilíbrio psicossomático e aos consequentes limites que irão fazer parte da vida do sujeito. A autosatisfação depende de encontrar o fio para costurar os elementos da existência a partir de um novo molde de sentido possibilitando uma nova identidade.
A costura de uma nova identidade acontece pela narrativa, que reconstrói a biografia a partir de novos referenciais. 0 profissional precisa estar atento, à escuta dessas narrativas de reconstrução da identidade para que a aplicação de meios terapêuticos produza o efeito esperado, para que o enfermo se sinta sujeito dos processos e assuma com autonomia as mudanças necessárias em sua vida.

\section{AGRADECIMENTOS}

À Lucilda Selli (in memorian) por ter estado presente em todas as fases da pesquisa

\section{Conflito de interesse: não há}

\section{SUMMARY}

Making sense of the narRatives of chronically IlL Persons

OBJECTIVE. Understand how chronically ill persons reframe life through their discursive practices.

METHODS. Six interviews were selected from the original seventeen made with chronically ill persons from a public hospital in the metropolitan region of Porto Alegre. Recorded and transcribed interviews produced narratives concerning the existential situation in the face of disease, perspectives for the future, a comprehension of diagnosis and of therapy as well as the role of professionals for the reframing. Talks were divided in linguistic repertoires concerning diagnosis and therapy.

RESULTS. In the first, the narratives of meaning are structured around cause of the disease from a genetic background (destiny) or due to the style of life (fault). In the repertoires about therapy, narratives of the self identity reconfiguration depend on the autonomy or heteronomy in relation to the physician's words as mediator of salvation, on perception of the body as a factor of relation, on the social representation of medication and on emotional situation.

CONCLUSION. Self-satisfaction relies on finding the thread to bring together the elements of existence based on a new model permitting a new identity. The professional must be involved in the narratives of identity reconstruction enabling therapy to produce the expected effect and for the patient to feel as a participant of the process, assuming with autonomy the necessary changes in life. [Rev Assoc Med Bras 2010; 56(2): 179-85]

KeY WORDS: Chronic disease. Diagnosis. Therapeutics. Personal narratives. Individuality.

\section{REFERÊNCIAS}

1. Brasil. Ministério da Saúde. Humaniza SUS. Política Nacional de Humanização. A humanização como eixo norteador das práticas de atenção em todas as instâncias do SUS. Brasília (DF): Ministério da Saúde; 2004.

2. Bakhtin M. Marxismo e filosofia da linguagem. São Paulo: Hucitec; 1986.

3. Brandão HHN. Introdução à análise do discurso. Campinas: Unicamp; 1991

4. Orlandi EP. Análise do discurso: princípios e procedimentos. $6^{\text {a }}$ ed. Campinas: Pontes Editores; 2005.

5. Spink MJ. Linguagem e produção de sentidos no cotidiano. Porto Alegre: Edipucrs; 2004.

6. Flick U. Uma introdução à pesquisa qualitativa. Porto Alegre: Bookman; 2005.

7. Gill R. Análise de discurso. In: Bauer MW, Gaskell G. Pesquisa qualitativa com texto, imagem e som: um manual prático. Petrópolis: Vozes; 2003. p.244-70.

8. Spink MJ, Lima H. Rigor e visibilidade: a explicitação dos passos da interpretação. In: Spink MJ, organizador. Práticas discursivas e produção de sentidos no cotidiano: aproximações teóricas e metodológicas. São Paulo: Cortez; 1999. p.93-122. 
9. Illich I. A expropriação da saúde. Nêmesis da Medicina. Rio de Janeiro: Nova Fronteira; 1981.

10. Giddens A. Modernidad e identidad del Yo: el yo y la sociedad en la época contemporánea. Barcelona: Ediciones Península; 1995.

11. Ricoeur P. Sí mismo como otro. Madrid: Siglo XXI Editores; 1996.

12. Alves PCB, Rabelo MCM. Significação e metáforas na experiência da enfermidade. In: Rabelo MCM, Alves PCB, Souza IMA. Experiência da doença e narrativa. Rio de Janeiro: Fiocruz; 1999. p.171-85.

13. Rodrigues JC. Os corpos na antropologia. In: Minayo MCS, Coimbra CEA organizadores. Críticas e atuantes. Ciências Sociais e Humanas em Saúde na América Latina. Rio de Janeiro: Fiocruz; 2005. p.157-82.

14. Rodrigues JC. O corpo na história. Rio de Janeiro: Fiocruz; 1999.

15. Borges ZN. Motivações para doar e receber: estudo sobre transplante renal entre vivos. In: Duarte LFD, Leal OF, organizadores. Doença, sofrimento, perturbação: perspectivas etnográficas. Rio de Janeiro: Fiocruz; 1998. p.169-79.

16. Lefèvre F. O medicamento como mercadoria simbólica. São Paulo: Cortez; 1991.
17. Pignarre PH. O que é o medicamento? Um objeto estranho entre ciência, mercado e sociedade. São Paulo: Editora 34; 1999.

18. Rabelo MCM, Alves PCB. Tecendo o Self e emoção nas narrativas de nervoso. In: Rabelo MCM, Alves PCB, Souza IMA. Experiência da doença e narrativa. Rio de Janeiro: Fiocruz; 1999. p.187-204.

19. Mead M. Espíritu, persona y sociedad. Buenos Aires: Paidós; 1988.

20. Duarte LFD. Indivíduo e pessoa na experiência da saúde e da doença. Ciênc Saúde Coletiva. 2003;8(1):173-83

Artigo recebido: 19/10/09 Aceito para publicação: 20/01/10 